\title{
Evaluation of drug release from paclitaxel + hirudin-eluting balloons and the resulting vascular reactivity in healthy pigs
}

\author{
XIAN WANG ${ }^{*}$, HONGMEI LI* ${ }^{*}$ XIAOTING SUN, XIAOHANG WANG and GANGYIN WANG \\ Institute for Cardiovascular Disease, Dongzhimen Hospital Affiliated to Beijing University \\ of Chinese Medicine, Beijing 100700, P.R. China
}

Received February 12, 2018; Accepted August 16, 2018

DOI: $10.3892 /$ etm.2018.6653

\begin{abstract}
This study explored drug release from paclitaxel + hirudin-eluting balloons in a healthy pig coronary artery model and objectively evaluated the vascular reactivity after balloon intervention. A total of 12 healthy white pigs were used for the analysis of drug release from the experimental balloon. The observational time-points included immediately following implantation and day 7, 30, and 180 after surgery. At each time-point, two pigs were treated with the paclitaxel + hirudin-eluting balloon and one with the B. Braun paclitaxel-eluting balloon (control). Quantitative coronary angiography (QCA) of the target vessel was performed before and after balloon treatment. One pig died before the designated experimental endpoint, and no abnormal clinical signs or tissue lesions were observed in the other pigs. QCA showed different degrees of spasms after balloon treatment, all of which recovered shortly thereafter without intervention. The blood vessel lumens were all open and without dissection or angioma. Drug content determination showed that the experimental balloon performed better than the control balloon with regard to drug release, vascular absorption and expulsion rate. The paclitaxel + hirudin-eluting balloon catheter was easy to manipulate. The drug release from the experimental balloon was stable and resulted in good vascular reactivity. The safety and efficacy of the experimental balloon were not worse than the paclitaxel-eluting balloon that is currently on the market.
\end{abstract}

\section{Introduction}

Although percutaneous coronary intervention (PCI) has become the standard treatment for stenotic coronary artery

Correspondence to: Professor Xian Wang, Institute for Cardiovascular Disease, Dongzhimen Hospital Affiliated to Beijing University of Chinese Medicine, 5 Haiyuncang, Beijing 100700, P.R. China

E-mail:wnb8p8@163.com

*Contributed equally

Key words: drug-eluting balloon, coronary artery invention, drug release, vascular reactivity, restenosis diseases, the incidence of restenosis can reach 10-60\% after the balloon catheter and stent are placed (1). Even when a drug-eluting stent (DES) is used, restenosis still occurs, with an incidence of $10-20 \%$. Furthermore, because the drug that is intended to inhibit vascular smooth muscle cells delays the re-endothelialization of the vascular intima, the risk of stent thrombosis formation has also become another dilemma in intervention therapy $(2,3)$.

Coronary smooth muscle cell proliferation and migration induce hyperplasia of the vascular intima, which is the main reason for post-PCI restenosis. Delayed vascular endothelialization caused by coating drugs that are used to inhibit the proliferation of smooth muscle cells is the key factor responsible for delayed thrombosis $(4,5)$. Based on previous research and the recent advancements in modern pharmacology, the current team optimized the anti-proliferation drug loading technique via vacuum coating and selected paclitaxel and hirudin for the coronary balloon catheter to prepare paclitaxel + hirudin-eluting balloons, with the aim to explore the feasibility of compound drug-eluting balloons for the treatment of coronary artery diseases. As a microtubular inhibitor, paclitaxel is highly liposoluble (10,000 times more liposoluble than rapamycin); because of this advantage, paclitaxel has been widely applied in stent/balloon elution as an anti-cell proliferation drug (6). In contrast, hirudin is a direct thrombin inhibitor that possesses high water solubility. The current team applied paclitaxel and hirudin to the balloon in a specific ratio. Hirudin serves as the carrier of paclitaxel. Their combination may inhibit the proliferation of vascular smooth muscle cells maximally but that of vascular endothelial cells minimally, thereby preventing restenosis and delayed thrombosis after PCI.

In a previous study conducted by our team, a cell co-culture system was used to stimulate the action mode of the paclitaxel + hirudin compound on vascular smooth muscle cells and vascular endothelial cells in rabbits, and the half maximal effective concentration of the paclitaxel + hirudin compound on the inhibition of proliferation and migration of rabbit smooth muscle cells and endothelial cells was determined (7). Furthermore, we explored the effect of the paclitaxel + hirudin compound on rabbit vascular endothelial and smooth muscle cells using a cell co-culture technique to determine the satisfactory ratio of paclitaxel to hirudin (to maximally inhibit smooth muscle cells and to minimally inhibit endothelial 
cells simultaneously) (8). The results showed that paclitaxel combined with a small dosage of hirudin $(3.13 \mu \mathrm{g} / \mathrm{ml}) \mathrm{did}$ not have a noticeable inhibitory effect on the growth of rabbit vascular endothelial cells in vitro, but it had a significant inhibitory effect on the growth of rabbit smooth muscle cells. Considering the differences between animal and human cells in tolerance and response to drug stimulation, the current team used human coronary smooth muscle and endothelial cells to determine the optimal ratio of paclitaxel to hirudin for human cells, and the results showed that the optimal concentrations were $1 \mu \mathrm{mol} / 1$ paclitaxel and $0.39 \mathrm{mg} / \mathrm{ml}$ hirudin, which can be used to develop drug-eluting balloons (9-11).

Based on the previous studies, in this study, we prepared paclitaxel + hirudin-eluting balloons according to the predetermined optimal ratio. Using the SeQuent Please paclitaxel-coated balloon (B. Braun Melsungen AG, Melsungen, Germany) as the control, which is already on the market, this study investigated the drug release from the paclitaxel + hirudin compound-coated balloon in the coronary arteries of healthy white pigs within 180 days and evaluated the interventional effect of the experimental balloon on vascular reactivity. The results of this study can provide data to support clinical experiments in the related field and may shed new light on the development of compound-eluting balloons.

\section{Materials and methods}

Materials. Domesticated pigs were provided by Nanhui Huaxin Special Animal Farm (Shanghai, China) and the animals met the SOP315 quarantine criteria. The drug-eluting balloon catheters included 23 Lepu balloons $(3.0 \times 15 \mathrm{~mm}$; batch no. DB1509001; Lepu Medical, Beijing, China) and 12 B. Braun balloons (3.0x16 mm; batch no. 15126809; B. Braun Melsungen AG). Paclitaxel was purchased from the Jiangsu Yew Pharmaceutical Co., Ltd. (purity, 97.7\%; batch no. 20131001; Wuxi, China). Terfenadine (article no. T9652-25G; batch no. 078k1345; purity, 100\%), buspirone hydrochloride (article no. B7148-1G; batch no. BCBL7606V; purity, 100\%), methanol (article no. 34860-4L-R; batch no. WXBB7001V), and acetonitrile (article no. 34851-4L; batch no. WXBC0095V) were purchased from Sigma-Aldrich: Merck KGaA (St. Louis, MO, USA). Formic acid (article no. 50144; batch no. 1203436) was from DikmaPure (Beijing, China).

The laboratory and surgical equipment included a vertical chamber, ultra-cold freezer (DW-86L628; Qingdao Haier Co., Ltd., Qingdao, China), a Heraeus Multifuge X3R centrifuge (Thermo Fisher Scientific, Inc., Waltham, MA, USA), an API 4000 spectrometer (Shanghai AB SCIEX Analytical Instrument Trading Co., Shanghai, China), an LC-20AD high-performance liquid chromatograph (Shimadzu Corp., Kyoto, Japan), an autosampler (SIL-20AC/HT; Shimadzu Corp.), a pressure pump (batch no. 201501011; KDL, Zhejiang, China), an Innova 2100-IQ digital imaging system, and standard interventional and auxiliary consumable materials [i.e., 7-F puncture sheath set (batch no. 201511038), 0.035" x $150 \mathrm{~cm}$ guidewire (batch no. 201510033) (both from KDL), 6-F guide catheter (batch no. 201506033; Lepu Medical), and guidewire (batch no. 201510033; Beijing Tiandi Hexie Technology Co., Ltd., Beijing, China)].
Methods. In each animal, each of the coronary arteries was treated with one balloon. The pressure holding time was $50 \mathrm{sec}$. An upstream 17-mm-long vascular section located $5 \mathrm{~mm}$ away from the balloon inflation site was sampled as the control sample, and the 17-mm-long section at the inflation site was used as the experimental sample for drug content analysis.

All treatment procedures performed in this study were approved by the Institute for Animal Ethics at Dongzhimen Hospital Affiliated to Beijing University of Chinese Medicine (Beijing, China) [approval no. Hui Zhi Ying Hua (2015) 1230 Gateway (2015/12)].

Animal grouping. The pigs were divided into the following time-point groups: instant, day 7, 30, and 180 groups. In each group, one pig for the control balloon and two pigs for the experimental balloons were used.

Angiography and balloon treatment. The balloon treatment was performed aseptically. The pigs were subjected to general anaesthesia. The day before surgery, a one-time dose of aspirin [325 mg, per os (PO)] and clopidogrel (150 mg, PO) was given to each pig. During the postoperative observational period, $100 \mathrm{mg}$ of aspirin and $75 \mathrm{mg}$ clopidogrel were administered PO each day until the experiment ended. Before the last follow-up after balloon treatment, two blood samples were taken from each pig. One sample was anti-coagulated with EDTA for drug content analysis and the other was not anti-coagulated. In addition, blood samples were taken for analysis instantly after inflation of each balloon during surgery. Before surgery, heparin sodium solution at $150 \mathrm{U} / \mathrm{kg}$ was administered via vein, and the activated clotting time (ACT) was monitored to ensure the value was $>300$ during the operation. The surgical procedures are shown in Fig. 1A-C. During the operation, real-time monitoring of haemodynamics, electrocardiography (ECG) and oxygen saturation levels $\left(\mathrm{SpO}_{2}\right)$ were performed. The balloon was guided into the coronary artery to reach the target site with the aid of a guide catheter and 0.014 " guidewire (Fig. 1D and E). The balloon was inflated with the pressure pump to ensure that the balloon sufficiently attached to the vessel wall. After $50 \mathrm{sec}$ of pressure holding, the pressure was removed and the guides were withdrawn. After the treatment, angiography was performed to assess the condition of the treated vascular section. After surgery, all apparatus and equipment were removed. After anaesthesia recovery, the pigs were observed until the designated survival time-points. After the observation was completed, the pigs were subjected to anaesthesia again for blood sampling. Approximately 12,500 U heparin sodium injection was intravenously administered, and then angiography was performed to observe the treated vascular section. After re-examination, the pigs were sacrificed by intravenous infusion of potassium chloride (20 mg equivalent/head) after general anaesthesia with 2-2.5\% sevoflurane inhalation. Autopsy was immediately performed.

Paclitaxel content determination. A homogenate of the vessel wall was prepared with water in a 1:9 ratio (w/v). Approximately $50 \mu \mathrm{l}$ of the vessel wall homogenate or whole-blood sample was mixed well with $200 \mu$ l of precipitant (1:1 methanol to acetonitrile containing $5 \mathrm{ng} / \mathrm{ml}$ buspirone as the internal standard). The sample was centrifuged at 2,504 $\mathrm{xg}$ 

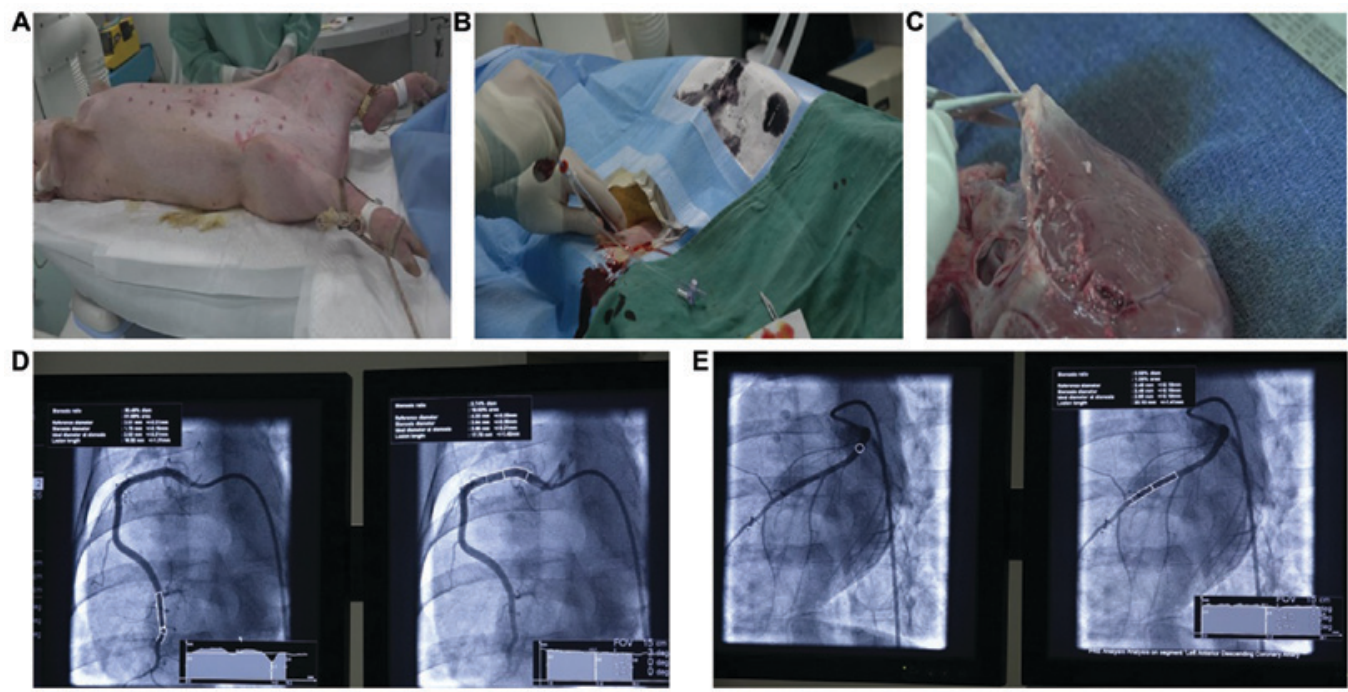

Figure 1. Treatment procedures. (A) Animal preparation. (B) Anaesthesia and venous puncture. (C) Separation of the coronary artery. (D) Right coronary arteriography and selection of the inflation section. (E) Left coronary arteriography and selection of the inflation section.

A

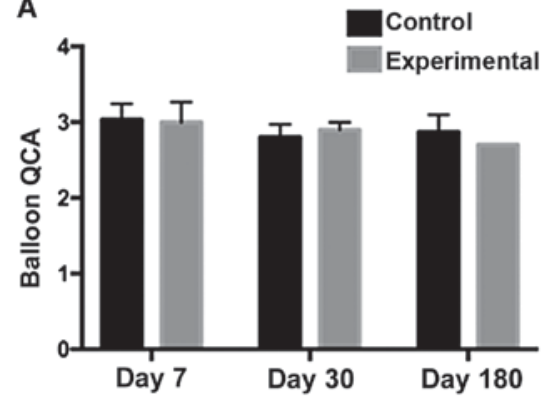

c

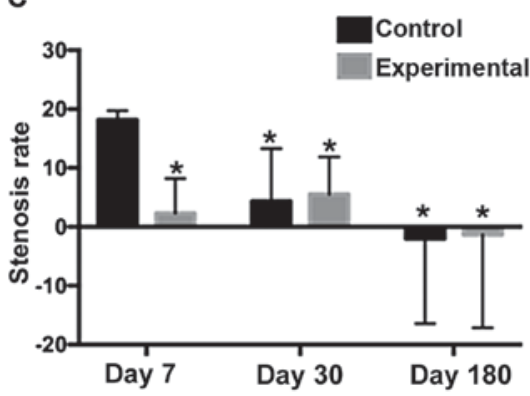

B

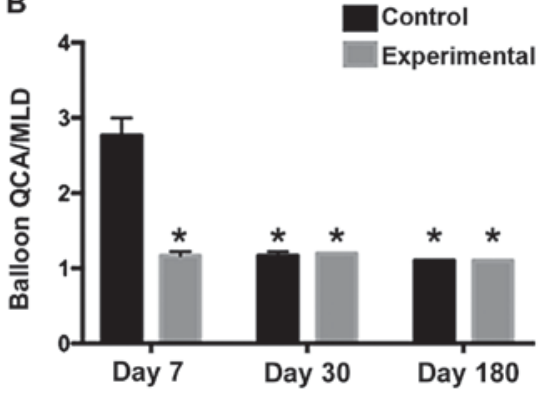

D

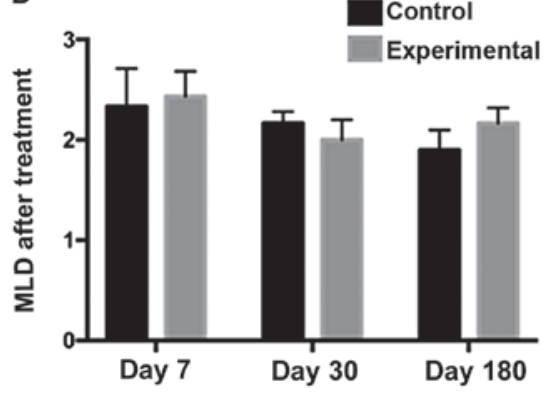

Figure 2. Comparison of the QCA outcomebetween the control and experimental groups at different time-points after treatment. (A) Balloon QCA: The maximum diameter of the balloon delivered during balloon treatment. Compared between the two groups, there is no difference in the vascular treatment lumen of the balloon. (B) MLD: minimum vascular lumen diameter. QCA/MLD refers to the treated vessel diameter/minimum vascular lumen diameter. When the restenosis occurs, the diameter of the smallest vascular lumen decreases, and the whole ratio increases. The larger the QCA/MLD, the more severe the restenosis. The comparison between the two groups showed that the degree of restenosis in the experimental group was less severe than that in the control group in the early stage (7 days) after intervention, which was an indirect method for determining the degree of restenosis. (C) As a direct method to judge the degree of restenosis, the restenosis rate of the two groups was compared. (D) After balloon treatment. MLD: diameter of the artery balloon segment, indicating no difference in lumen diameter immediately after treatment. ${ }^{*} \mathrm{P}<0.05$ vs. the control group at day 7 . QCA, quantitative coronary angiography.

and $4^{\circ} \mathrm{C}$ for $15 \mathrm{~min}$. The supernatant was collected and diluted with $0.1 \%$ formic acid solution to twice the volume. Liquid chromatography-electrospray ionization-tandem mass spectrometry (LC-ESI-MS/MS) was then performed.

Statistical analysis. Data are presented as the mean \pm standard deviation (SD) and were processed with SPSS version 20.0 software (IBM Corp., Armonk, NY, USA). One-way analyses of variance were used for comparisons among groups, and $\mathrm{t}$-tests were used for comparisons between groups. $\mathrm{P}<0.05$ was considered statistically significant.

\section{Results}

General health condition. During the experiment, none of the groups showed adverse clinical signs except for one pig in the 

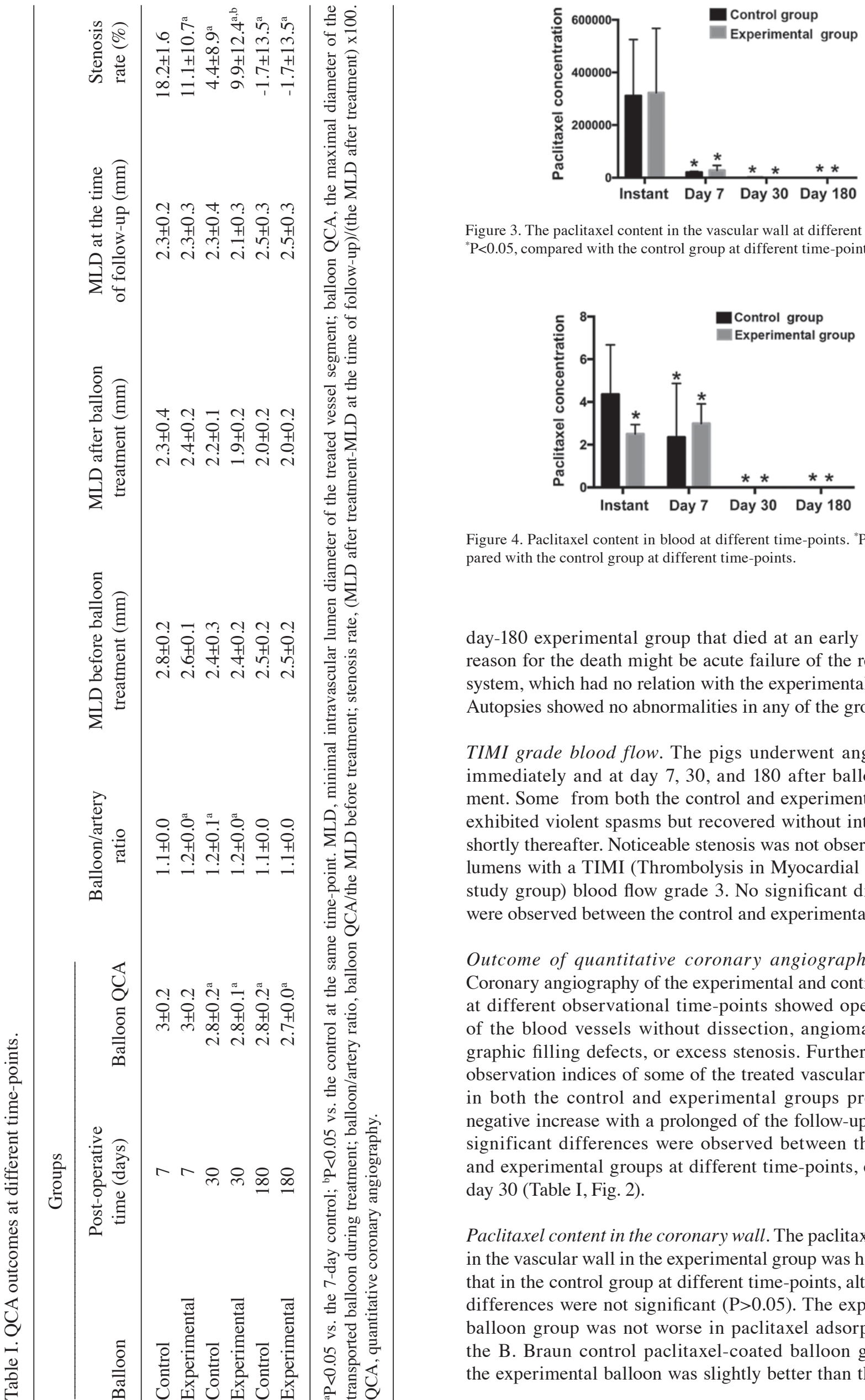

Figure 3. The paclitaxel content in the vascular wall at different time-points. ${ }^{*} \mathrm{P}<0.05$, compared with the control group at different time-points.

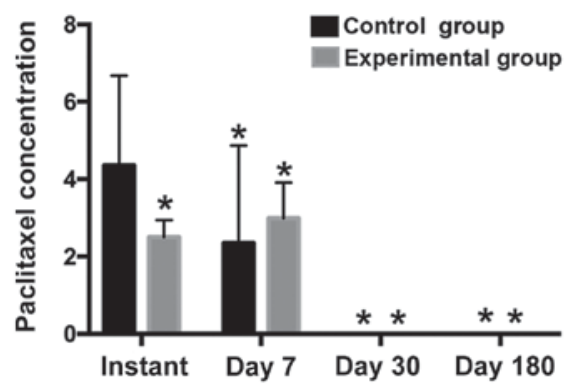

Figure 4. Paclitaxel content in blood at different time-points. " $\mathrm{P}<0.05$, compared with the control group at different time-points.

day-180 experimental group that died at an early stage (the reason for the death might be acute failure of the respiratory system, which had no relation with the experimental balloon). Autopsies showed no abnormalities in any of the groups.

TIMI grade blood flow. The pigs underwent angiography immediately and at day 7, 30, and 180 after balloon treatment. Some from both the control and experimental groups exhibited violent spasms but recovered without intervention shortly thereafter. Noticeable stenosis was not observed in the lumens with a TIMI (Thrombolysis in Myocardial Infarction study group) blood flow grade 3 . No significant differences were observed between the control and experimental groups.

Outcome of quantitative coronary angiography (QCA). Coronary angiography of the experimental and control groups at different observational time-points showed open lumens of the blood vessels without dissection, angiomas, angiographic filling defects, or excess stenosis. Furthermore, the observation indices of some of the treated vascular segments in both the control and experimental groups presented a negative increase with a prolonged of the follow-up time. No significant differences were observed between the control and experimental groups at different time-points, except for day 30 (Table I, Fig. 2).

Paclitaxel content in the coronary wall. The paclitaxel content in the vascular wall in the experimental group was higher than that in the control group at different time-points, although the differences were not significant $(\mathrm{P}>0.05)$. The experimental balloon group was not worse in paclitaxel adsorption than the B. Braun control paclitaxel-coated balloon group, but the experimental balloon was slightly better than the control 
Table II. Paclitaxel content in the coronary wall.

\begin{tabular}{|c|c|c|c|c|c|c|c|c|}
\hline \multirow{3}{*}{$\begin{array}{l}\text { Groups } \\
\text { Control }\end{array}$} & \multirow{2}{*}{$\begin{array}{c}\text { Postoperative } \\
\text { time-point (days) } \\
\text { Instant }\end{array}$} & \multirow{3}{*}{$\begin{array}{l}\begin{array}{c}\text { Sample } \\
\text { section }\end{array} \\
\text { Control } \\
\text { Treated }\end{array}$} & \multicolumn{3}{|c|}{ Paclitaxel concentration (ng/g) } & \multicolumn{3}{|c|}{ Total content of paclitaxel (ng) } \\
\hline & & & 6,250 & 65,000 & 8,360 & 338 & 2,509 & 487 \\
\hline & & & 534,000 & 293,000 & 108,000 & 19,544 & 7,735 & 3,629 \\
\hline \multirow[t]{2}{*}{ Experimental } & Instant & Control & 47,600 & 28,300 & 21,000 & 2,675 & 849 & 903 \\
\hline & & Treated & 605,000 & 167,000 & 196,000 & 2,509 & 487 & 31,823 \\
\hline \multirow[t]{2}{*}{ Experimental } & Instant & Control & 10,400 & 13,300 & 6,060 & 924 & 871 & 496 \\
\hline & & Treated & 56,300 & 410,000 & 137,000 & 2,871 & 14,883 & 6,713 \\
\hline \multirow[t]{2}{*}{ Control } & 7 & Control & 56.7 & 52.0 & 61.8 & 2.98 & 1.46 & 2.04 \\
\hline & & Treated & 23,000 & 16,400 & 22,200 & 736 & 531 & 571 \\
\hline \multirow{2}{*}{ Experimental } & 7 & Control & 259 & 399 & 64.8 & 8.88 & 11.6 & 1.83 \\
\hline & & Treated & 36,900 & 38,000 & 5,510 & 1,524 & 1,041 & 147 \\
\hline \multirow[t]{2}{*}{ Experimental } & 7 & Control & 35.2 & 1,150 & 201 & 0.901 & 15 & 4.82 \\
\hline & & Treated & 14,600 & 40,100 & 5,810 & 283 & 1,528 & 97.6 \\
\hline \multirow[t]{2}{*}{ Control } & 30 & Control & 0 & 103 & 0 & 0 & 2 & 6.73 \\
\hline & & Treated & 0 & 2,820 & 1,400 & 0 & 69.7 & 51.1 \\
\hline \multirow[t]{2}{*}{ Experimental } & 30 & Control & 0 & 0 & 0 & 0 & 0 & 0 \\
\hline & & Treated & 0 & 161 & 588 & 2 & 6.73 & 13.8 \\
\hline \multirow[t]{2}{*}{ Experimental } & 30 & Control & 0 & 913 & 0 & 0 & 26.3 & 0 \\
\hline & & Treated & 291 & 31.5 & 264 & 10.2 & 0.488 & 5.65 \\
\hline \multirow[t]{2}{*}{ Control } & 180 & Control & 0 & 0 & 0 & 0 & 0 & 0 \\
\hline & & Treated & 21.8 & 0 & 39.0 & 0.953 & 0 & 1.53 \\
\hline \multirow[t]{2}{*}{ Experimental } & 180 & Control & 0 & 0 & 0 & 0 & 0 & 0 \\
\hline & & Treated & 38 & 27.2 & 0 & 0 & 0 & 0 \\
\hline
\end{tabular}

Table III. Paclitaxel content in blood.

\begin{tabular}{|c|c|c|c|c|c|}
\hline \multirow[b]{2}{*}{ Groups } & \multirow{2}{*}{$\begin{array}{l}\text { Postoperative } \\
\text { time (days) }\end{array}$} & \multirow[b]{2}{*}{ Blood-sampling time } & \multicolumn{3}{|c|}{ Paclitaxel concentration (ng/ml) } \\
\hline & & & $\mathrm{RCA}$ & LCA & LAD \\
\hline \multirow[t]{2}{*}{ Control } & \multirow[t]{2}{*}{ Instant } & Before treatment & 0 & 0 & 0 \\
\hline & & After treatment & 2.28 & 6.86 & 3.92 \\
\hline \multirow[t]{2}{*}{ Experimental } & \multirow[t]{2}{*}{ Instant } & Before treatment & 0 & 0 & 0 \\
\hline & & After treatment & 0 & 0 & 2.91 \\
\hline \multirow[t]{2}{*}{ Experimental } & \multirow[t]{2}{*}{ Instant } & Before treatment & 0 & 0 & 0 \\
\hline & & After treatment & 2.04 & 3.99 & 2.57 \\
\hline \multirow[t]{2}{*}{ Control } & \multirow[t]{2}{*}{7} & Before treatment & 0 & 0 & 0 \\
\hline & & After treatment & 2.05 & 0 & 5.01 \\
\hline \multirow[t]{2}{*}{ Experimental } & \multirow[t]{2}{*}{7} & Before treatment & 0 & 0 & 0 \\
\hline & & After treatment & 7.97 & 3.93 & 2.95 \\
\hline \multirow[t]{2}{*}{ Experimental } & \multirow[t]{2}{*}{7} & Before treatment & 0 & 0 & 0 \\
\hline & & After treatment & 4.74 & 3.77 & 2.09 \\
\hline \multirow[t]{2}{*}{ Control } & \multirow[t]{2}{*}{30} & Before treatment & 0 & 0 & 0 \\
\hline & & After treatment & 0 & 0 & 0 \\
\hline \multirow[t]{2}{*}{ Experimental } & \multirow[t]{2}{*}{30} & Before treatment & 0 & 0 & 0 \\
\hline & & After treatment & 0 & 0 & 0 \\
\hline \multirow[t]{2}{*}{ Experimental } & \multirow[t]{2}{*}{30} & Before treatment & 0 & 0 & 0 \\
\hline & & After treatment & 3.86 & 4.56 & 4.04 \\
\hline \multirow[t]{2}{*}{ Control } & \multirow[t]{2}{*}{180} & Before treatment & 0 & 0 & 0 \\
\hline & & After treatment & 0 & 0 & 0 \\
\hline \multirow[t]{2}{*}{ Experimental } & \multirow[t]{2}{*}{180} & Before treatment & 0 & 0 & 0 \\
\hline & & After treatment & 0 & 0 & 0 \\
\hline
\end{tabular}


balloon in transient paclitaxel release and the anchoring effect of paclitaxel on the vascular wall (Table II, Fig. 3).

Paclitaxel content in blood. The paclitaxel content in blood in the experimental group was lower than that in the control group, particularly in the instant time-point group $(\mathrm{P}<0.05)$. The expulsion rate of the experimental balloon group was lower than that of the control balloon group, implying better safety and drug stability (Table III, Fig. 4).

\section{Discussion}

Currently, the incidence of thrombosis after treatment with new-generation DESs has decreased to $0.2 \%$ (12). Although the incidence of thrombosis after PCI is low, the consequences of thrombosis are severe, including a high mortality, and it is the main reason for death after interventional surgery. Therefore, decreasing the risk of thrombosis has become a focus for the research and development of balloons and stents (13).

The development of peri-PCI thrombus primarily involves two steps: thrombin activation and platelet activation, in which clot retraction serves as a connecting link in the process. Apart from transforming fibrinogen into fibrin to participate in the clotting process, thrombin induces direct and indirect thrombin-mediated interactions between molecules and cells by activating thrombin receptors (14). With the cascade of reactions in the clotting process, thrombin increases the permeability of the endothelium to cause a series of vascular injuries. Furthermore, thrombin promotes a proliferative response after vascular injury by exerting the function of growth hormones. In addition, thrombin forms a complex network with platelets, protein kinases and adhesion molecules. Therefore, thrombin not only initiates restenosis, but it is active through the whole process. Effective inhibition of thrombin is of significance in the treatment of anti-cell proliferation and restenosis. Theoretically, effective anti-coagulation and anti-platelet treatments will help decrease the incidence of thrombosis. However, a study was conducted among 8,402 patients with stenotic coronary artery diseases in whom Cypher and Taxus stents were implanted (15). Among these patients, confirmed stent thrombosis was found in 83 patients and potential stent thrombosis was observed in 127 patients. Furthermore, 66\% of the patients with confirmed/potential stent thrombosis reported good compliance with clopidogrel. These observations indicate that even patients with good compliance with clopidogrel are not exempt from the risk of stent thrombosis. These data pose the question of how ticagrelor, a newly developed powerful P2Y12 receptor antagonist, will perform in preventing stent thrombosis. For patients who underwent PCI, pre-hospital ticagrelor administration at a loading dose or in-hospital ticagrelor administration did not prevent thrombosis; the proportion of the patients who received pre-hospital ticagrelor was $0.2 \%$ and that of the patients who received in-hospital ticagrelor was $1.2 \%$ at day 30 after surgery $(\mathrm{P}=0.02)$. In addition, ticagrelor failed to noticeably improve the TIMI blood flow condition or ST-segment resolution before PIC (13). Therefore, even the use of a new type of anti-platelet drugs cannot prevent thrombosis completely, and more effective anti-thrombosis and anti-cell proliferation strategies are warranted.
Currently, stents and balloons coated with paclitaxel have been widely applied in clinical practice with satisfactory safety and effectiveness. As a microtubule inhibitor, paclitaxel primarily inhibits the G0/G1 and G2/M stages of the cell cycle, and it inhibits spindle formation, transmembrane signal transduction and gene expression related to cell division to inhibit microtubule-dependent cellular physiological processes, such as proliferation, migration and secretion $(16,17)$. Paclitaxel-eluting stents significantly decrease the incidence of in-stent restenosis, as well as the incidence of adverse cardiac events and target lesion revascularization $(6,18)$. It is worth mentioning that paclitaxel-coated balloons also present unequalled advantages compared with other drug-coated balloons. Presently, all drug-coated balloons on the market use paclitaxel as the anti-proliferative drug. Paclitaxel is highly liposoluble, which allows it to be absorbed rapidly by cells through the cell membrane. Moreover, the one-time embedding technique of balloons can produce a long-lasting anti-hyperplasia effect, which is suitable for local transport of drugs. Furthermore, paclitaxel, even at micromolar concentrations, can effectively inhibit the proliferation and migration of vascular smooth muscle cells. Therefore, paclitaxel-coated balloons have a broad prospect in anti-restenosis applications (18). B. Braun SeQuent Please balloons arrived on the market in 2004. In the product, the dosage of paclitaxel is $3 \mu \mathrm{g} / \mathrm{mm}^{2}$, the matrix is Ultravist 370 , and the drug release time during balloon inflation is $30-60 \mathrm{sec}$. However, numerous studies have shown that the incidence of restenosis after implantation of the paclitaxel-eluting stent can reach up to $10-20 \%$. The delayed thrombosis has greatly limited the clinical application of paclitaxel-eluting stents, and the occurrence of delayed thrombosis and restenosis is primarily associated with the inhibitory effect of paclitaxel on the proliferation and migration of intimal smooth muscle cells (19-26).

Hirudin is a direct thrombin inhibitor. The no. 63 tyrosine in natural hirudin is sulphated and can act on the non-active substrate-recognition site and enzyme active centre of thrombin to play an anti-coagulation role (27). Different from heparin, the inhibitory and deactivation effect of hirudin on thrombin does not rely on anti-thrombin III and II, protein C or tissue factor pathway inhibitors, and it does not combine with platelets which dampens activity. Hirudin inhibits thrombin-induced platelet aggregation; therefore, it possesses good anti-coagulation and anti-thrombotic effects (28). Bivalirudin, a recombinant, new-generation derivative of hirudin, displays an excellent anti-coagulation effect and clinical curative effect (29). Even more, the Chinese guidelines for PCI (2016) recommended intravenous injection of bivalirudin 3-4 h after PCI to reduce preoperative complications (30). Studies on rabbit models of arterial injury showed that short-term treatment with hirudin reduced the neointimal area by $44-59 \%$ (31,32). More than 10 years ago, an endothelial-friendly' drug stent was developed, in which recombinant hirudin and iloprost were combined (33). This stent was tested in pig and goat animal experiments, and the results showed that hirudin + iloprost-coated stents decreased the risk of thrombosis and effectively reduced the restenotic area of the coronary artery. This type of stent provided the current team with a new idea for a combined drug loading technique: that a combination of two monomers for balloon/stent coating 
may effectively decrease post-PCI restenosis incidence and prevent thrombosis. Natural hirudin has biological immunogenicity, and it can work as a satisfactory template to guide the restoration of vascular tissue. The combination of paclitaxel and hirudin for eluting has anti-proliferation and thrombosis-preventing effects and does not influence the restoration of vascular tissue. The paclitaxel + hirudin combination may be the best design concept of drug-eluting balloons.

The results of this study showed that paclitaxel + hirudin-eluting balloons effectively inhibited intimal proliferation and significantly decreased the incidence of restenosis at different time-points within 180 days follow-ups. In protecting residual vessel lumens and decreasing restenosis rate, the effects of the experimental balloon were not worse or better than those of the on-sale paclitaxel-eluting balloon. Hirudin, serving as the carrier for paclitaxel, mediates the slow release of paclitaxel, which might be one of the main mechanisms underlying the effects of this combination on inhibiting intimal proliferation and preventing/curing restenosis. Before balloon inflation, the compound-eluting balloon catheter was easy to manipulate. After surgery, angiography showed clear images of the balloon-treated vascular sections. Observations of the local anatomy did not show vascular necrosis, vascular thinning or inflammatory exudation. Determination of paclitaxel contents in the vascular wall and blood showed that the concentrations were both within the non-toxic range, which indicates that the local concentration of hirudin-mediated paclitaxel release is safe, and without noticeable toxic effects or side-effects. According to LC-ESI-MS/MS, the instant release of paclitaxel and the instant absorption of paclitaxel by the vascular wall in the experimental group was better than those parameters in the control group. The follow-up at day 180 showed that the paclitaxel content in the vascular wall was stable and robust in the experimental group, which effectively prevented the incidence of restenosis caused by the proliferation of vascular smooth muscle cells. The determination of paclitaxel content in the blood samples showed that the expulsion rate of paclitaxel in the experimental group was lower than that in the control group, which corresponds to better safety and drug stability with an improved long-term effect of the experimental balloon compared with that of the control balloon.

In conclusion, the new type of paclitaxel + hirudin-eluting balloons utilized in this study possesses excellent safety and histocompatibility, which can effectively prevent late thrombosis, preserve the residual lumen area, and decrease restenosis incidence. However, the drug release and absorption processes of the studied balloon in vivo may require a longer observational time. The preventive effect of the paclitaxel + hirudin-eluting balloon on post-PCI restenosis needs a larger sample size for validation. Furthermore, the working micro-mechanism remains to be explored.

\section{Acknowledgements}

Not applicable.

\section{Funding}

This study was supported by the National Natural Science Foundation of China (no. 81273913) and Scientific
Grants of Beijing University of Chinese Medicine (no. 2013-ZDXKKF-27).

\section{Availability of data and materials}

The datasets used and/or analyzed during the current study are available from the corresponding author on reasonable request.

\section{Authors' contributions}

HL and XianW conceived and designed the study, and wrote the article. HL, XiaohangW and GW conducted the experiments and collected the data. XS conducted the analysis, and XianW supervised the whole process and gave constructive advice. All authors have read and approved the final manuscript.

\section{Ethics approval and consent to participate}

This study was approved by the Ethics Committee of Dongzhimen Hospital Affiliated to Beijing University of Chinese Medicine (Beijing, China).

\section{Patient consent for publication}

Not applicable.

\section{Competing interests}

The authors declare that they have no competing interests.

\section{References}

1. Dietz U, Dauer C and Lambertz H: Combining short stent implantation and drug-eluting stenting for routine use yields a low restenosis rate. Exp Clin Cardiol 11: 294-297, 2006.

2. Gurvitch R, Lefkovits J, Warren RJ, Duffy SJ, Clark DJ, Eccleston D, Yan BP, Reid C, Brennan A, Andrianopoulos N, et al: Clinical outcomes of drug-eluting stent use in patients with ST elevation myocardial infarction. Int J Cardiol 143: 283-288, 2010.

3. Ghattas A, Shantsila E and Lip GY: Antithrombotic therapy after percutaneous coronary intervention in anticoagulated patients: A fine balance between thrombosis and bleeding. Ther Adv Cardiovasc Dis 5: 5-9, 2011.

4. Stone GW, Lansky AJ, Pocock SJ, Gersh BJ, Dangas G, Wong SC Witzenbichler B, Guagliumi G, Peruga JZ, Brodie BR, et al; HORIZONS-AMI Trial Investigators: Paclitaxel-eluting stents versus bare-metal stents in acute myocardial infarction. N Engl J Med 360: 1946-1959, 2009.

5. Oduncu V, Erkol A, Tanboğa IH and Kırma C: Late bare metal stent thrombosis. Türk Kardiyol Dern Arş - Arch Turk Soc Cardiol 38: 422-425, 2010.

6. Heldman AW, Cheng L, Jenkins GM, Heller PF, Kim DW, Ware M Jr, Nater C, Hruban RH, Rezai B, Abella BS, et al: Paclitaxel stent coating inhibits neointimal hyperplasia at 4 weeks in a porcine model of coronary restenosis. Circulation 103: 2289-2295, 2001.

7. Wang $X$ and Zhao HB: Effects of paclitaxel hirudin complex on proliferation and migration of vascular smooth muscle cells and endothelial cells of rabbits. Chin J Evid Based Cardiovasc Med 1: 65-69, 2009.

8. Wang $\mathrm{X}$ and Zhao HB: Effects of paclitaxel hirudin complex on the growth of rabbit vascular endothelial cells and smooth muscle cells (unpublished PhD thesis). Shanxi Medical University, 2011.

9. Li HM and Wang X: Influence of hirudin on growth of in vitro human coronary artery smooth muscle cells and human coronary artery endothelial cells. Chin J Evid Based Cardiovasc Med 7: 792-794,797, 2015 
10. Li HM and Wang X: Influence of lipopolysaccharide on growth of in vitro human coronary artery smooth muscle cells: An investigation on establishing in-stent restenosis inflammatory cells model. Chin J Evid Based Cardiovasc Med 8: 29-33, 2016.

11. Li HM and Wang X: Influence of lipoposaccharide (LPS) on expressions of inflammatory factors of in vitro human coronary artery smooth muscle cells (HCASMC): An investigation on establishing in-stent restenosis inflammation cell model. Chin J Evid Based Cardiovasc Med 8: 297-301, 2016.

12. Jensen LO, Thayssen P, Christiansen EH, Maeng M, Ravkilde J, Hansen KN, Hansen HS, Krusell L, Kaltoft A, Tilsted HH, et al SORT OUT IV Investigators: Safety and efficacy of everolimus-versus sirolimus-eluting stents: 5-year results from SORT OUT IV. J Am Coll Cardiol 67: 751-762, 2016.

13. Montone RA, Hoole SP and West NE: Prehospital ticagrelor in ST-segment elevation myocardial infarction. N Engl J Med 371: 2338-2339, 2014.

14. van Hinsbergh VW: Endothelium - role in regulation of coagulation and inflammation. Semin Immunopathol 34: 93-106, 2012.

15. Puricel S, Cuculi F, Weissner M, Schmermund A, Jamshidi P Nyffenegger T, Binder H, Eggebrecht H, Münzel T, Cook S, et al: Bioresorbable coronary scaffold thrombosis: Multicenter comprehensive analysis of clinical presentation, mechanisms, and predictors. J Am Coll Cardiol 67: 921-931, 2016

16. Yvon AM, Wadsworth P and Jordan MA: Taxol suppresses dynamics of individual microtubules in living human tumor cells. Mol Biol Cell 10: 947-959, 1999.

17. Xin S, Yu F, Yang C and Hao X: Inhibition of paclitaxel against neuroglioma cells u251 growth and its mechanism. Afr J Tradit Complement Altern Med 14: 174-178, 2016.

18. Ellis SG, Kereiakes DJ, Metzger DC, Caputo RP, Rizik DG, Teirstein PS, Litt MR, Kini A, Kabour A, Marx SO, et al; ABSORB III Investigators: Everolimus-eluting bioresorbable scaffolds for coronary artery disease. N Engl J Med 373: 1905-1915, 2015.

19. Gerber RT, Latib A, Ielasi A, Cosgrave J, Qasim A, Airoldi F, Chieffo A, Montorfano M, Carlino M, Michev I, et al: Defining a new standard for IVUS optimized drug eluting stent implantation: The PRAVIO study. Catheter Cardiovasc Interv 74: 348-356, 2009

20. Hong MK, Mintz GS, Lee CW, Park DW, Choi BR, Park KH, Kim YH, Cheong SS, Song JK, Kim JJ, et al: Intravascular ultrasound predictors of angiographic restenosis after sirolimus-eluting stent implantation. Eur Heart J 27: 1305-1310, 2006.

21. Joner M, Finn AV, Farb A, Mont EK, Kolodgie FD, Ladich E, Kutys R, Skorija K, Gold HK and Virmani R: Pathology of drug-eluting stents in humans: Delayed healing and late thrombotic risk. J Am Coll Cardiol 48: 193-202, 2006.

22. Lee CW, Kang SJ, Park DW, Lee SH, Kim YH, Kim JJ, Park SW, Mintz GS and Park SJ: Intravascular ultrasound findings in patients with very late stent thrombosis after either drug-eluting or bare-metal stent implantation. J Am Coll Cardiol 55: 1936-1942, 2010

23. Morice MC, Serruys PW, Sousa JE, Fajadet J, Ban Hayashi E, Perin M, Colombo A, Schuler G, Barragan P, Guagliumi G, et al; RAVEL Study Group. Randomized study with the sirolimus-coated Bx Velocity Balloon-Expandable Stent in the treatment of patients with de novo native coronary artery lesions: A randomized comparison of a sirolimus-eluting stent with a standard stent for coronary revascularization. N Engl J Med 346 $1773-1780,2002$
24. Moses JW, Leon MB, Popma JJ, Fitzgerald PJ, Holmes DR, O'Shaughnessy C, Caputo RP, Kereiakes DJ, Williams DO, Teirstein PS, et al; SIRIUS Investigators: Sirolimus-eluting stents versus standard stents in patients with stenosis in a native coronary artery. N Engl J Med 349: 1315-1323, 2003.

25. Moses JW, Dangas G, Mehran R and Mintz GS: Drug-eluting stents in the real world: How intravascular ultrasound can improve clinical outcome. Am J Cardiol 102 (Suppl): 24J-28J, 2008.

26. Pfisterer M, Brunner-La Rocca HP, Buser PT, Rickenbacher P, Hunziker P, Mueller C, Jeger R, Bader F, Osswald S and Kaiser C; BASKET-LATE Investigators: Late clinical events after clopidogrel discontinuation may limit the benefit of drug-eluting stents: An observational study of drug-eluting versus bare-metal stents. J Am Coll Cardiol 48: 2584-2591, 2006.

27. Warkentin TE: Bivalent direct thrombin inhibitors: Hirudin and bivalirudin. Best Pract Res Clin Haematol 17: 105-125, 2004.

28. He L, Vicente CP, Westrick RJ, Eitzman DT and Tollefsen DM: Heparin cofactor II inhibits arterial thrombosis after endothelial injury. J Clin Invest 109: 213-219, 2002

29. Lincoff AM, Bittl JA, Kleiman NS, Sarembock IJ, Jackman JD, Mehta S, Tannenbaum MA, Niederman AL, Bachinsky WB, Tift-Mann J III, et al; REPLACE-1 Investigators: Comparison of bivalirudin versus heparin during percutaneous coronary intervention (the Randomized Evaluation of PCI Linking Angiomax to Reduced Clinical Events [REPLACE]-1 trial). Am J Cardiol 93: 1092-1096, 2004.

30. Section of Interventional Cardiology of Chinese Society of Cardiology of Chinese Medical Association; Specialty Committee on Prevention and Treatment of Thrombosis of Chinese College of Cardiovascular Physicians; Editorial Board of Chinese Journal of Cardiology: Chinese guidelines for percutaneous coronary intervention (2016). Zhonghua Xin Xue Guan Bing Za Zhi 44: 382-400, 2016 (In Chinese).

31. Thome LM, Gimple LW, Bachhuber BG, McNamara CA Ragosta M, Gertz SD, Powers ER, Owens GK, Humphries JE and Sarembock IJ: Early plus delayed hirudin reduces restenosis in the atherosclerotic rabbit more than early administration alone: Potential implications for dosing of antithrombin agents. Circulation 98: 2301-2306, 1998.

32. Gerdes C, Faber-Steinfeld V, Yalkinoglu O and Wohlfeil S: Comparison of the effects of the thrombin inhibitor r-hirudin in four animal models of neointima formation after arterial injury. Arterioscler Thromb Vasc Biol 16: 1306-1311, 1996.

33. Alt E, Haehnel I, Beilharz C, Prietzel K, Preter D, Stemberger A, Fliedner T, Erhardt W and Schömig A: Inhibition of neointima formation after experimental coronary artery stenting: A new biodegradable stent coating releasing hirudin and the prostacyclin analogue iloprost. Circulation 101: 1453-1458, 2000.

This work is licensed under a Creative Commons Attribution-NonCommercial-NoDerivatives 4.0 International (CC BY-NC-ND 4.0) License. 